(2) OPEN ACCESS

\title{
Framework for evaluation research on clinical ethical case interventions: the role of ethics consultants
}

\author{
Joschka Haltaufderheide (1) ,' Stephan Nadolny (1) , 2,3 Jochen Vollmann, ${ }^{1}$ \\ Jan Schildmann ${ }^{2}$
}

${ }^{1}$ Institute for Medical Ethics and History of Medicine, Ruhr University, Bochum, Germany ${ }^{2}$ Institute for History and Ethics of Medicine, Interdisciplinary Center for Health Sciences, Martin Luther University, HalleWittenberg, Germany ${ }^{3}$ Nursing Science Staff Unit, Franziskus Hospital Harderberg, Niels-Stensen-Kliniken, Germany

\section{Correspondence to}

Dr Joschka Haltaufderheide, Institute for Medical Ethics and History of Medicine, Ruhr University Bochum, Bochum 44799, Germany;

joschka.haltaufderheide@ruhruni-bochum.de

Received 2 December 2020 Revised 9 March 2021 Accepted 8 April 2021
Check for updates

(C) Author(s) (or their employer(s)) 2021. Re-use permitted under CC BY-NC. No commercial re-use. See rights and permissions. Published by BMJ.

To cite: Haltaufderheide J, Nadolny S, Vollmann J, et al. I Med Ethics Epub ahead of print: [please include Day Month Year]. doi:10.1136/ medethics-2020-107129

\section{ABSTRACT}

Evaluation of clinical ethical case consultations has been discussed as an important research task in recent decades. A rigid framework of evaluation is essential to improve quality of consultations and, thus, quality of patient care. Different approaches to evaluate those services appropriately and to determine adequate empirical endpoints have been proposed. A key challenge is to provide an answer to the question as to which empirical endpoints - and for what reasons - should be considered when evaluating the quality of a service. In this paper, we argue for an approach that adopts the role of ethics consultants as its point of departure. In a first step, we describe empirical and ethical characteristics of evaluating clinical ethical case. We show that the mode of action and the explicit normative character of the interventions constitute two characteristics which pose challenges to the selection of appropriate quality criteria and require special attention. In a second step, we outline the way in which an analysis of the role of ethics consultants in the context of a clinical ethical case consultation services can account for the existing challenges by linking empirically measurable endpoints with normative theory. Finally, we discuss practical implications of our model for evaluation research.

\section{BACKGROUND}

Ethical case consultations (ECC) have become a routine provision in hospitals and other healthcare facilities. ${ }^{1-3}$ They are positively rated by users, ${ }^{14-7}$ supported by representatives of the medical profession and other occupational groups, ${ }^{8-10}$ and have a legal standing in several countries. ${ }^{11}$

Evaluation research has been acknowledged as an important step towards further development of ECC for more than two decades. ${ }^{32-14}$ Recent years have witnessed the publication of quantitative $e^{15-20}$ and qualitative $^{2122}$ evaluation studies on various aspects of ECC. However, up to present there is lack of research which links the results and procedures of specific ECC with robust empirical endpoints. ${ }^{45} 12$ A key challenge is to provide an answer to the question as to which empirical endpoints- and for what reasons-should be considered when evaluating the quality of a service. ${ }^{3}$

Various difficulties have already been discussed with regard to this problem. These include the complexity of ECC as well as the ambiguity of endpoints such as patient mortality. ${ }^{23}{ }^{24}$ In contrast, the normative character of ECC as a relevant feature for the selection of endpoints has remained underexposed. In this paper, we argue for an approach to evaluation that uses the role of ethics consultants and underlying-often implicit—premises as point of departure. We start by outlining a common definition of evaluation research and, then, describe the normative character of ECC as a distinct feature of this type of intervention in healthcare. Second, we show that the explicitly normative character of ECC poses a decisive challenge to the selection of appropriate quality criteria. In a third step, we exemplify in which way an analysis of the roles of ethics consultants in the context of a specific service can account for those challenges by linking empirically measurable endpoints with normative theory.

\section{Normativity in evaluating ECC}

Evaluation research entails the assessment of a process, a structure or its outcomes based on information on the properties, activities or characteristics of the object of investigation. ${ }^{25}$ Two central challenges for the evaluation in the medical field have repeatedly been cited. First, every investigation must specify empirical endpoints, since it is a question of evaluating practical interventions and their effectiveness and not of theoretical concepts. ${ }^{25}$ This, second, presupposes not only an operationalisable but also a conceptually justifiable view of what ought to be expected of a given intervention. In the broadest sense, according to the definition above, evaluation research entails the application of quality criteria and their underlying value judgements to certain aspects, characteristics or dimensions. ${ }^{25}$ Hence, evaluating ECC means to develop a notion of what ought to be expected by an intervention and to assess whether or to what extent this expectations have been met by means of empirical research.

Fletcher and Siegler define ECC as a 'service provided by an individual consultant, team, or committee to address the ethical issues involved in a specific clinical case. Its central purpose is to improve the process and outcomes of patients' care by helping to identify, analyse, and resolve ethical problems. ${ }^{26}$

Since one of the primary touchstones of ECC is to improve patient care, ${ }^{27}$ a certain comparableness of ECC with other medical interventions is often suggested, implying similar quality criteria. However, this conceals two important characteristics of ECC which are also to be understood as delimiting criteria from typical medical interventions (eg, medication, surgery) and which are relevant for evaluating ECC.

The first characteristic relates to what we would like to call the mode of action. In the case of classical medical interventions, the immediate aim is to improve a health problem, whereas ECC deal with 
value conflicts which, among other things, are associated with differing interpretations of participants' rights and duties. ${ }^{27} 28$ In contrast to many (though not all) healthcare interventions, ECC does not address the health condition of the patient directly but influences the decision-making process as to how this condition should be treated. ${ }^{27}$ Whereas the possible endpoints of medical interventions can, thus, be more precisely limited to care and health parameters, as inferred from the medical problem, the more indirect mode of action in ECC leads to a multiplication of possible endpoints, as inferred from the whole decision-making process. $^{1}$

To be clear, the effective distinction between a classical medical intervention like administering a drug and ECC is not characterised by an unambiguous dividing line. Depending on their complexity and modes of action, other healthcare interventions may also impact on the elements of decision-making processes and, thus, possess a greater variety of endpoints. The mode of action is a matter of degree. While some medical interventions confine their impact directly to health conditions and some others, often more complex ones, also can affect the decisionmaking process, ECC services usually aim at the decision-making process and, more seldom, influence health conditions directly.

In addition to its mode of action, ECC are distinguishable from other medical interventions by what we would like to call an explicit normative character: a considerable part of ECC is devoted to questions of appropriate action. Although there may be different positions regarding the question as to how ECC should impact on decisions in clinical practice, ${ }^{13}$ they all have in common that they rely on 'strong' intrinsic value perspectives. In comparison with typical medical intervention, these value judgements are based explicitly on ethical concepts and claim to occupy a privileged position over and above other value judgements. To give an example, a classical medical intervention, such as the healing of a broken arm, may be based on the idea that what is 'good' is what causes bones to grow together or contributes to functional capability. Undeniably, this is also based on normative judgements, which are, however, sustained predominantly from a medical-functional standpoint. Its effectiveness could be assessed by aligning to this perspective: the intervention is good if the bones grow together and the more effectively the better it is from a medical-functional perspective. The same applies to other perspectives which are based on such functional values, such as an economic perspective or an assessment from the perspective of patient satisfaction. Each of these perspectives would certainly justify a specific set of quality criteria. The distinguishing feature of such functional perspective is that they satisfy a certain goal (eg, improving patient care), whereby other perspectives and standards of value are inferior. By contrast, ECC are based on the idea of something morally good which transcends such functional perspectives: 'morally good' is not (only) good in a functional, medical or economic sense, but good after weighing up all the interests. Hence, concerning ethics, a 'non-partisan' standard of value comes into play.

This does not imply that there are no conflicting values in ethics. First, the criterion of explicit normativity refers to the definition of ethics as 'considering all relevant interests' compared with value perspectives that do not. And again, as with the first difference, the continuum is gradual. While in medical interventions different functional perspectives can be-and often are implicitly-weighed against each other, ECC mark the other end of a continuum between a singular functional perspective and the explicit consideration of a more universal perspective. Second, this does, however, not mean that there are no considerable differences about the idea of a non-partisan standard itself.
Especially in pluralistic societies, a variety of different concepts of ethics can been set into place. This reflects the considerable differences which exist regarding the question what ethics is actually about, what its basic principles are (if there are any) or what its procedures of deliberation might be, suggesting, of course, different approaches to consider what ought to be done.

Explicit normativity as well the mode of action have implications when answering the question as to how ECC might be evaluated. Both determine where and how an intervention impacts on healthcare. First, the indirect mode of action of ECC leads to a multiplication of possible endpoints eligible as quality criterion. Second, the evaluation of ECC is concerned with an intervention in which explicit normativity is of crucial importance. It therefore-more than evaluation of other interventions-has to be aware of a 'duplication of value judgements'. This duplication refers first to the fact that in ECC, strong value judgements, along with the ethical theory that underpins them, are applied to guide results, working practices and goals of a decision-making process. Second, value judgements are embedded within the framework of evaluation to assess the adequacy of these results, working practices and goals. However, if a non-partisan standard comes into play as discussed above, it seems hardly possible to evaluate whether this standard has been met adequately without aligning to its perspective. Consider, for example, an intervention based on an idea of ethics in which consensual understanding and patient self-determination are of great importance. Based on this premise, space and time for mutual understanding is more important than quick and efficient decisions and the preservation of patient autonomy might in some cases outweigh medical optimal choices. According to the underlying idea of ethics, cases taking their time or cases in which patient autonomy trumps optimal medical choices have to be considered as being processed in an ethical way and therefore fulfil the aim of the intervention. However, failing to align with this perspective and, for example, asking how efficient the decisionmaking process was does not reflect this and thus does not seem to represent a reasonable expectation. Considering the fact that underlying ethical ideas might differ between interventions and cannot be presupposed right away, ${ }^{29}$ an adequate account of the basic ethical idea must be given as starting point of evaluation to align evaluative quality criteria with the interventions' basic normative standard. Failure to do so could otherwise result in the specific ethical character of the intervention being masked by the imposition of external perspectives, bearing the risk of creating false and misleading expectations of what ought to be achieved.

\section{Reconstruction of normativity as a starting point for evaluation research}

The above analysis shows that evaluation of ECC is faced with at least two challenges. First, the sheer number of possible endpoints hampers the selection of appropriate empirical quality criteria. Second, ECC is itself of a normative-especially ethical-character. The challenge here is to reflect this ethical character in evaluation criteria to avoid imposition of external or inferior value perspectives. The task, as we conclude it therefore, is to give an account of the intervention of ECC that captures the basic ethical rationale and thereby reduces the range of possible outcomes to those, which reflect the ethical rationale. In practice, however, grasping the normative standard of a particular ECC and orienting one's evaluation criteria towards it have proven to be very difficult. ECC services are usually complex and dynamic entities evolving over time and influenced by many different factors. Their normative standard rarely exists as a 
detailed ethical theory, but is often an implicit part of operational practices.

Our proposal to deal with these challenges is, therefore, based on a pragmatic and reconstructive approach, centring on the role of ethics consultants in the context of ECC. We define 'role' as a bundle of tasks and activities assigned to a person as a structural element of an intervention. By pragmatism, defined as rejection of ideas that have impractical consequences, we mean that it seems to be unpromising to challenge the multiplicity of endpoints of ECC, the role or variety of normative theory by, for example, defending a certain idea of ethics. By calling this approach reconstructive, on the other hand, we consider it to be a consequence of this concession that the normative standard an evaluation of ECC needs to align with can only be the one embedded in the intervention under investigation and, consequently, has to be made explicit first. We propose to focus on the role of ethics consultants and to move from the 'embodied' normative standard in their operational practices forward to an explication of normative presuppositions.

Focusing on the role of ethics consultants has several advantages. First, definitions of ECC univocally presuppose consultants as experts for the purposes of identifying, analysing and resolving ethical conflicts. ${ }^{30} 31$ Second and more important, ethics consultants can be understood as being equipped with a special knowledge, skills or both to be able to fulfil their predestined role. Properties defining this knowledge and skills largely depend on the meaning and concepts of ethics which is applied. Thus, the role of ethics consultants encapsulates important assumptions in ethical theory and epitomises certain approaches, methods and goals, each of which results from a certain concept of ethics. While the role of an ethics consultant is a structural element of most ECC and has an empirically measurable impact on the processes and outcomes of an intervention by way of their actions, its influence can directly be attributed to those characteristics inherent in the normative standard of an intervention.

\section{Illustrating the idea}

To illustrate the potential of our proposal, we will briefly summarise different levels of the discussion on two possible roles of ethics consultants and implications for evaluation. With this approach, we do not want to contribute to the discussion as to which concept of consultant roles is appropriate and should be applied in practice. In addition, we do not assume that the models we reflect on represent the full range of possible concepts. However, we have chosen these roles in light of their contrasting normative premises, serving our aim to exemplify how our approach can be used to identify relevant distinctions in consultants' operational practices which thereafter can be used for evaluation.

Practices defining the role of ethics consultants in identifying, analysing and resolving ethics issues have, for example, been described on numerous occasions including the consensus statement by Fletcher and Siegler. ${ }^{26}{ }^{32-36}$ On one hand, this includes tasks of ethical analysis, that is, to enrich ethical deliberation with substantial contributions content-wise, ${ }^{32}$ to specify normative concepts, ${ }^{33} 34$ analyse or advocate arguments and resist errors, justify and defend a certain suggestion for further action and take an own moral standpoint. ${ }^{26}$ On the other hand, consultants should also engage in process and dialogue and increase reflexivity ${ }^{35}$ by inclusion of all parties in the discussion, improvement of communication, assisting in clarification of personal moral views and facilitation of a consensus. ${ }^{32-34} 36$

These descriptions display a bandwidth of possible consultant roles $^{37}$ and not a description of one single consultant's doing.
This is attributable to more than one normative standard referring to different epistemological and meta-normative premises. The first cluster of descriptions conceives the ethicist as a moral problem-solver. He or she fulfils an analytical role and adds to the process by a substantial contribution content-wise. ${ }^{38} 39$ According to Steinkamp and Gordijn, the second cluster depicts the role of an ethics consultant as an observer and facilitator. ${ }^{38} 39$ His or her role is to keep himself or herself free of the content while the aim is to involve participants in a dialogic process, creating mutual understanding that enables further action to be taken by consensus.

The first cluster of tasks stands for a more traditional understanding of ethics. In principle, this view is determined by the independence of moral facts or moral reasoning and justification. With this premise, it is implied that individuals, by virtue of their skills and knowledge, are able to recognise and analyse moral issues. It is further assumed that a trained person is in a better position to do so allowing consultants to acquire a special set of skills, knowledge and techniques to be able to engage in identification, analysis and solution of moral problems. ${ }^{38} 4041$ According to Margaret Walker, this renders an ethics consultant as a 'technically equipped specialist for moral input' whose task it is to inject his or her knowledge on different levels of deliberation. ${ }^{41}$

The second cluster on the other hand testifies to a hermeneutically shaped and phenomenologically grounded understanding of ethics. In this view, ethics is rooted not in abstract principles derived from reason, but in experiences and specific understanding of a certain situation at hand. It is assumed as a necessary prerequisite that this understanding can change and, at best, can develop towards a mutual understanding. Hence, hermeneutic ethics aims to explore the basic perspectives in a constructive dialogue to develop a richer understanding and to arrive at consensual conclusions rooted in the experiences of participants of a deliberation. ${ }^{42}$ In this view, no one can claim to have superior insight into a moral problem but has to accept the subjectivity of his or her perspective. Developing a process of mutual understanding based on the moral intuitions and competences of participants becomes more important. The consultants' role consequently consists in primarily promoting a dialogue and connecting subjective moral perspectives. The initial part of table 1 gives an overview on the different roles and associated tasks.

Both positions described here have been repeatedly criticised for the basic assumptions of their ethical theory. ${ }^{33} 3841$ Analytical models are often understood as being too authoritative, for example, by shifting the moral decision towards consultants. Hermeneutical models have been criticised for their arbitrariness and lack of theory. However, apart from this continuing discussion about the right understanding of ethics itself, one can see that explicating the dividing line between a hermeneutic and an analytical understanding of ethics enables us to capture how fundamental assumptions of the normative standard influence operational practices of ethics consultants. In turn, it becomes easier to form reasonable expectations about quality criteria of respective ECC. With regard to normative standards from the spectrum of hermeneutic ethics, evaluation research can focus on the assessment of the communicative process. If ethical thinking is based on the participants' contextual perception and can only succeed if their perspectives and experiences complement each other, then this also exposes the decisive criterion for the quality of a corresponding intervention. Ethical considerations can only succeed where a hermeneutic process of confrontation between different perspectives on equal footing can be developed. 
Table 1 Roles and endpoints according to normative premises

\begin{tabular}{|c|c|}
\hline Hermeneutic role of ethics consultant & Analytical role of ethics consultant \\
\hline 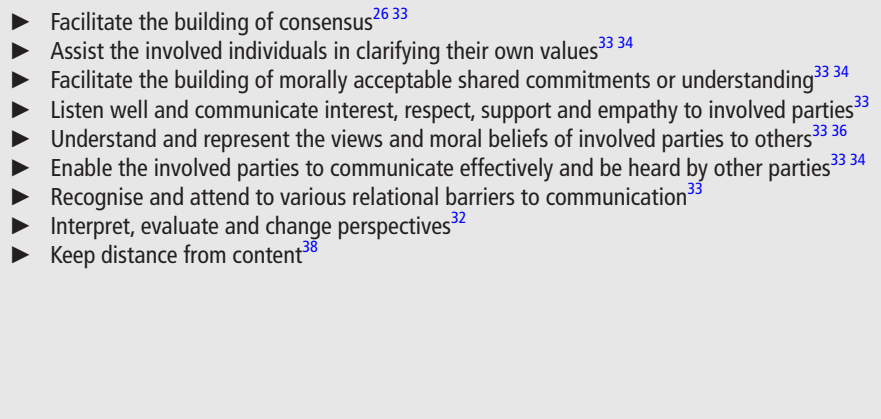 & 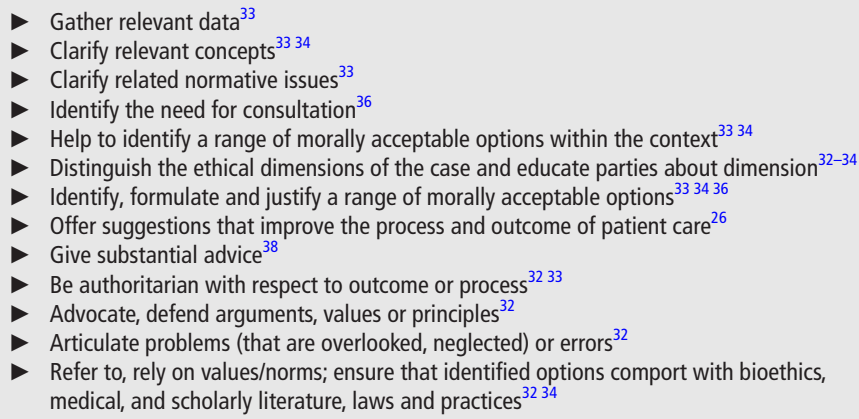 \\
\hline
\end{tabular}

ECC, ethical case consultations.

Meaningful endpoints must refer to the subjective experiences of participants ${ }^{43}$ in the communicative process and evaluate the extent to which they have been successfully integrated. This would mean to evaluate whether interprofessional communication improved, ${ }^{43-45}$ whether the consultant managed to build a relationship between parties ${ }^{46}$ or a certain team spirit was developed. ${ }^{44}$ It could also include to evaluate whether participants feel on equal footing in regard to power and access. ${ }^{19} 2143$

The analytical idea on the other hand implies independent criteria on the basis of which one can judge the appropriateness of a certain course of action. It, first, seems reasonable to expect interventions relying on this standard to be able to guide the further course of decision-making and action and, second, to do this more effectively than other interventions not depending on the input of a moral specialist. Such an intervention should therefore be able to demonstrate that it is more effective than comparable interventions, for example, in terms of its costeffectiveness or the number of cases handled. ${ }^{344748}$ This, as well, includes improvements in patients' outcomes ${ }^{26}$ or decisionmaking processes ${ }^{41845}$ as they can be perceived by different stakeholders. In addition, the ability of ethics consultants to identify ethical issues as well as to apply their knowledge to a case comes into focus. ${ }^{194546}$ This narrows the focus of endpoints to dimensions of influence on decision-making processes, for example, how helpful a consultation was in determining the further course of treatment, whether it successfully advanced the solution of an ethical problem or prevented its escalation, or whether patients and relatives see their wishes and preferences sufficiently considered. For an illustration of the connection between clustered roles and tasks and respective endpoints, see table 1 .

This rationale complements existing approaches of evaluation with an important step. Ethics consultants as well as researchers in the field are provided with a concrete and conceptually founded starting point to determine how the evaluation of an intervention can be aligned with given normative priorities. They are provided with a framework that is capable of narrowing down and controlling the selection and scope of the endpoints. To be able to put this framework into research practice, a first step in this direction is to transform the exemplary distinction between hermeneutic and analytical approach described above into a guideline for self-assessment or third-party assessment. Table 2 gives an overview on possible questions to include in such a guideline to steer reflection or observation of an intervention.

\section{Limitations and future research directions}

We concede that there are limitations of our analysis. The reconstruction illustrated here refers to two general ideas of ECC, which are not only highly contrastive, but have been described also in a detailed manner with respect to theoretical premises in the literature. However, in most cases of ECC, this theoretical substructure is not, or only partially, determined, whereas the reconstruction is considerably more complex. A full analysis of a specific intervention would, by no doubt, require to carefully gather additional data to allow for a reconstruction. Our approach in the context of this work necessitates that our analysis has taken recourse to more general concepts. No additional primary data were collated which would allow for an on-site reconstruction of a specific form.

The dividing lines presented here represent only a first distinction, which needs to be further elaborated. Further normative premises whose influence on the role of ethics consultants can be assumed and which therefore might be worth considering could be the distinction between casuistic and universalistic understanding of ethics or the role of normative principles and justifications for framing and description of ethical problems. Furthermore, factors could be considered with which ethical theories define the range and inclusion of stakeholders as, for example, between a communitarian approach and a liberal view.

In order to use these and other possible categories productively, however, further empirical research is needed. The connection between different ethical premises and possible endpoints presented here is by no means conclusive. At this 
Table 2 Checks for hermeneutic/analytical role of ethics consultants

\begin{tabular}{lll}
\hline $\begin{array}{l}\text { How does the ethics consultant } \\
\text { contribute to... }\end{array}$ & Hermeneutic role & Analytical role \\
\hline Identification of ethical problems? & By understanding and representing views of and to others & By gathering of relevant data \\
& By assisting in clarification of participants' individual views & By clarification of concepts \\
Analysis of ethical problems? & By creating shared understanding & By distinguishing ethical problems from other dimensions \\
& By attending parties to communicate & By resisting on errors \\
& By keeping distance from content & By referring to/relying on norms \\
Solution of ethical problems? & By facilitating of consensus building & By offering suggestions to improve \\
& By facilitating of acceptable shared commitments & Bnowledge \\
& & By taking and defending own moral perspective \\
\hline
\end{tabular}

point, evaluation research must expand and supplement the spectrum of available endpoints. This applies not only with regard to the operationalisation of further indices, but above all to the expansion of the spectrum of methods, in order to be able to describe the entire range of effects of ECC and to gather and analyse corresponding data.

Finally, one question relevant to research as well as to ECC practice arising from our approach concerns the process of certification of ethics consultants as an important step in improving quality of ECC. Distinguishing between different normative approaches of ECC raises the question whether and to what extent these different approaches can be certified in a common process which can be applied to ECC regardless of their normative premises. Future approaches in certification must be aware of this challenge. They have to find a common ground of skills and knowledge for the process of attestation and at the same time have to consider whether and to what extent it is necessary to take into account expertise which is bound to certain normative theories.

Contributors JH and JS conceived of the presented Idea. JH, JS and SN developed the first outline of the theory. JV contributed to theory development. JH wrote the manuscript with support from JS. All authors discussed the results, contributed to and approved the final version of the manuscript.

Funding This paper contains results obtained within the BMBF-funded research project 'Systematische Übersichtsarbeit zur Effektivität von ethischer Einzelfallberatung bei Erwachsenen Patienten in der letzten Lebensphase' (A Systematic Review of the Effectiveness of Ethical Individual Case Consultation in Adult Patients in the Last Phase of Life) (FK: 01KG 1404)

Competing interests None declared.

Patient consent for publication Not required.

Provenance and peer review Not commissioned; externally peer reviewed.

Data availability statement There are no data in this work.

Open access This is an open access article distributed in accordance with the Creative Commons Attribution Non Commercial (CC BY-NC 4.0) license, which permits others to distribute, remix, adapt, build upon this work non-commercially, and license their derivative works on different terms, provided the original work is properly cited, appropriate credit is given, any changes made indicated, and the use is non-commercial. See: http://creativecommons.org/licenses/by-nc/4.0/

ORCID iDs

Joschka Haltaufderheide http://orcid.org/0000-0002-5014-4593

Stephan Nadolny http://orcid.org/0000-0002-6826-6433

\section{REFERENCES}

1 Dörries A, Hespe-Jungesblut K. Die Implementierung Klinischer Ethikberatung in Deutschland. Ethik Med 2007:19(2):148-56.

2 Fox E, Myers S, Pearlman RA. Ethics consultation in United States hospitals: a national survey. Am J Bioeth 2007;7(2):13-25.
3 Pfäfflin M, Kobert K, Reiter-Theil S. Evaluating clinical ethics consultation: a European perspective. Camb Q Healthc Ethics 2009;18(4):406-19.

4 Craig JM, May T. Evaluating the outcomes of ethics consultation. J Clin Ethics 2006;17(2):168-80.

5 Doran E, Fleming J, Kerridge I. Clinical ethics support literature review. Sidney, 2015

6 Schochow M, May A, Schnell D. Wird Klinische Ethikberatung in Krankenhäusern in Deutschland implementiert? [Implementation of clinical ethics consultation in German hospitals]. Dtsch med Wochenschr 2014:139(43):2178-83.

7 Vollmann J. Klinische Ethikkomitees und Ethikberatung in Deutschland: Bisherige Entwicklung und zukünftige Perspektiven. Bioethica Forum 2008;1:33-9.

8 American Medical Association. Code of medical ethics. Opinion 10.7.1 2017. Available: https://www.ama-assn.org/sites/ama-assn.org/files/corp/media-browser/ code-of-medical-ethics-chapter-10.pdf [Accessed 25 Feb 2019].

9 Bundesärztekammer. Stellungnahme der Zentralen Kommission zur Wahrung ethische Grundsätze in der Medizin und ihren Grenzgebieten (Zentrale Ethikkommission) bei der Bundesärztekammer zur Ethikberatung in der klinischen Medizin. Dtsch Arztebl 2006;103(24):1703-7.

10 Schweizerische Akademie der Medizinischen Wissenschaften. Ethische Unterstützung in Der Medizin. 3rd ed. Basel, 2017.

11 Steinkamp N, Gordijn B, Borovecki A, et al. Regulation of healthcare ethics committees in Europe. Med Health Care Philos 2007;10(4):461-75.

12 Hoffmann DE. Evaluating ethics committees: a view from the outside. Milbank $Q$ 1993;71(4):677-701

13 Tulsky JA, Fox E. Evaluating ethics consultation: framing the questions. J Clin Ethics 1996;7(2):119-115.

14 Tulsky JA, Stocking CB. Obstacles and opportunities in the design of ethics consultation evaluation. J Clin Ethics 1996:7(2):139-45.

15 DuVal G, Clarridge B, Gensler G, et al. A national survey of U.S. internists' experiences with ethical dilemmas and ethics consultation. J Gen Intern Med 2004;19(3):251-8.

16 Kalager G, Førde R, Pedersen R. Is the discussion of patient cases in clinical ethicscommittees useful? Tidsskr Nor Laegeforen 2011;131(2):118-21.

17 La Puma J, Stocking CB, Darling CM, et al. Community hospital ethics consultation: evaluation and comparison with a university hospital service. Am J Med 1992;92(4):346-51.

18 McClung JA, Kamer RS, DeLuca M, et al. Evaluation of a medical ethics consultation service: opinions of patients and health care providers. Am J Med 1996:100(4):456-60.

19 Orr RD, Moon E. Effectiveness of an ethics consultation service. J Fam Pract 1993;36(1):49-53

20 Pearlman RA, Foglia MB, Fox E, et al. Ethics consultation quality assessment tool: a novel method for assessing the quality of ethics case consultations based on written records. Am J Bioeth 2016;16(3):3-14.

21 Kelly SE, Marshall PA, Sanders LM, et al. Understanding the practice of ethics consultation: results of an ethnographic multi-site study. J Clin Ethics 1997:8(2):136-49

22 Svantesson $M$, Löfmark $R$, Thorsén $H$, et al. Learning a way through ethical problems: Swedish nurses' and doctors' experiences from one model of ethics rounds. J Med Ethics 2008:34(5):399-406.

23 Williamson L. Empirical assessments of clinical ethics services: implications for clinical ethics committees. Clin Ethics 2007;2(4):187-92.

24 Schildmann J, Nadolny S, Haltaufderheide J, et al. Do we understand the intervention? what complex intervention research can teach us for the evaluation of clinical ethics support services (CESS). BMC Med Ethics 2019:20(1):48.

25 Donabedian A. Evaluating the quality of medical care. Milbank Mem Fund Q 1966;44(3):166-206

26 Fletcher JC, Siegler M. What are the goals of ethics consultation? a consensus statement. J Clin Ethics 1996;7(2):122-6.

27 Geppert CMA, Shelton WN. A comparison of general medical and clinical ethics consultations: what can we learn from each other? Mayo Clin Proc 2012;87(4):381-9. 
28 Aulisio MP, Arnold RM. Role of the ethics Committee: helping to address value conflicts or uncertainties. Chest 2008;134(2):417-24.

29 Inguaggiato G, Metselaar S, Porz R, et al. A pragmatist approach to clinical ethics support: overcoming the perils of ethical pluralism. Med Health Care Philos 2019;22(3):427-38.

30 Scofield GR, Fletcher JC, Jonsen AR. Ethics consultation: the least dangerous profession? Camb Q Healthc Ethics 1993;2(4):417-48.

31 Simon A, May AT, Neitzke G. Curriculum „Ethikberatung im Krankenhaus”. Ethik Med 2005;17(4):322-6

32 Reiter-Theil $\mathrm{S}$. Dealing with the normative dimension in clinical ethics consultation. Camb Q Healthc Ethics 2009;18(4):347-59.

33 Aulisio MP, Arnold RM, Youngner SJ. Health care ethics consultation: nature, goals, and competencies. A position paper from the Society for health and human ValuesSociety for bioethics consultation Task force on standards for bioethics consultation. Ann Intern Med 2000;133(1):59-69.

34 Tarzian AJ, Asbh Core Competencies Update Task Force 1. Health care ethics consultation: an update on core competencies and emerging standards from the American Society for bioethics and humanities' core competencies update Task force. Am J Bioeth 2013;13(2):3-13.

35 Magelssen M, Pedersen R, Førde R. Four roles of ethical theory in clinical ethics consultation. Am J Bioeth 2016;16(9):26-33.

36 Larcher V, Slowther A-M, Watson AR, et al. Core competencies for clinical ethics committees. Clin Med 2010;10(1):30-3.

37 Kornfeld DS. What is the role of a clinical ethics consultant? Am J Bioeth 2016;16(3):40-2.

38 Steinkamp NL, Gordijn B, ten Have HAMJ. Debating ethical expertise. Kennedy Inst Ethics J 2008;18(2):173-92.

39 Casarett DJ, Daskal F, Lantos J. The authority of the clinical ethicist. Hastings Cent Rep 1998;28(6):6.

40 Yoder SD. The nature of ethical expertise. Hastings Cent Rep 1998;28(6):11.

41 Walker MU. Keeping moral space open. New images of ethics consulting. Hastings Cent Rep 1993;23(2):33.

42 Weidema FC, Molewijk BAC, Kamsteeg F, et al. Aims and harvest of moral case deliberation. Nurs Ethics 2013;20(6):617-31.
43 Svantesson M, Karlsson J, Boitte $\mathrm{P}$, et al. Outcomes of moral case deliberation--the development of an evaluation instrument for clinical ethics support (the Euro-MCD). BMC Med Ethics 2014;15:30.

44 Tanner S, Albisser Schleger H, Meyer-Zehnder B. Klinische Alltagsethik Unterstützung im Umgang mit moralischem Disstress? Evaluation eines ethischen Entscheidungsfindungsmodells für interprofessionelle klinische Teams [Clinical everyday ethics - support in handling moral distress? Evaluation of an ethical decision-making model for interprofessional clinical teams]. Med Klin Intensivmed Notfmed 2014;109(5):354-63.

45 Hem MH, Pedersen R, Norvoll R, et al. Evaluating clinical ethics support in mental healthcare: a systematic literature review. Nurs Ethics 2015;22(4):452-66.

46 Fox E, Arnold RM. Evaluating outcomes in ethics consultation research. J Clin Ethics 1996;7(2):127-38.

47 Fox E. Concepts in evaluation applied to ethics consultation research. J Clin Ethics $1996 ; 7(2): 116-21$.

48 Bacchetta MD, Fins JJ. The economics of clinical ethics programs: a quantitative Justification. Camb Q Healthc Ethics 1997;6(4):451-60.

49 Schildmann J, Gordon J-S, Vollmann J. Clinical ethics consultation: theories and methods, implementation, evaluation. Farnham, Surrey, UK: Ashgate Pub, 2010.

50 Dowdy MD, Robertson C, Bander JA. A study of proactive ethics consultation for critically and terminally ill patients with extended lengths of stay. Crit Care Med 1998;26(2):252-9.

51 Gilmer T, Schneiderman LJ, Teetzel H, et al. The costs of nonbeneficial treatment in the intensive care setting. Health Aff 2005;24(4):961-71.

52 Heilicser BJ, Meltzer D, Siegler M. The effect of clinical medical ethics consultation on healthcare costs. J Clin Ethics 2000;11(1):31-8.

53 White BD, Zaner RM, Bliton MJ, et al. An account of the usefulness of a pilot clinical ethics program at a community hospital. QRB Qual Rev Bull 1993;19(1):17-24

54 Chen Y-Y, Chu T-S, Kao Y-H, et al. To evaluate the effectiveness of health care ethics consultation based on the goals of health care ethics consultation: a prospective cohort study with randomization. BMC Med Ethics 2014;15(1):1. 